\title{
Surface Reactions are Crucial for Energy Storage
}

\author{
Elsa Callini ${ }^{\star a b}$, Shunsuke Kato ${ }^{\mathrm{ab}}$, Philippe Mauron ${ }^{\mathrm{ab}}$, and Andreas Züttelab
}

\begin{abstract}
Reactions between gas molecules, e.g. $\mathrm{H}_{2}$ and $\mathrm{CO}_{2}$ and solids take place at the surface. The electronic states and the local geometry of the atomic arrangement determine the energy of the adsorbate, i.e. the initial molecule and the transition state. Here we review our research to identify the surface species, their chemical state and orientation, the interaction with the neighbouring molecules and the mobility of the adsorbed species and complement the experimental results with thermodynamic modelling. The role of the Ti was found to be a bridge between the charged species preventing the individual movement of the ions including charge separation. The Ti has no catalytic effect on the hydrogen sorption reaction in borohydrides. The physisorption of molecular hydrogen is too weak at ambient temperature to reach a significant hydrogen storage density. The addition of a hydrogen dissociation catalyst to a nanoporous material with a large specific surface area may potentially enable the spillover of hydrogen atoms from the metal catalyst to the surface of the porous material and chemisorb on specific sites with a much higher binding energy compared to physisorption. The intercalation of alkali metals in $\mathrm{C}_{60}$ fullerenes increases the interaction energy of hydrogen with the so-called metal fullerides significantly. Sterical diffusion barriers by partial oxidation of the surface of borohydrides turned out to redirect the reaction path towards pure hydrogen desorption and suppress the formation of diborane, a by-product of the hydrogen evolution reaction from borohydrides previously undetected. The combination of a newly developed gas controlling system with microreactors allows us to investigate complex reactions with small quantities of nano designed new catalytic materials. Furthermore, tip-enhanced Raman spectroscopy (TERS) will allow the investigation of the reactions locally on the surface of the catalyst and the near ambient pressure photoelectron spectroscopy enables analysis of the surfaces in ultra-high vacuum and in situ interaction with the adsorbates i.e. while the reaction takes place. This brings us in a unique position for the investigation of the heterogeneous reactive systems. The mechanism of the Ti catalysed hydrogen sorption reactions in alanates was recently established based on spectroscopic investigations combined with thermodynamic analysis of the transition states.
\end{abstract}

Keywords: $\mathrm{CO}_{2}$ reduction · Energy storage $\cdot$ Hydrogen $\cdot$ Spectroscopy $\cdot$ Surface reactions

\section{Introduction}

The closed hydrogen cycle has three sectors, i.e. hydrogen production by electrolysis, hydrogen storage, and hydrogen combustion. The cycle allows storage of renewable energy and is realized by technical means alone. The hydrogen cycle does not contain carbon and is therefore $\mathrm{CO}_{2}$ neutral. The main challenge of the hydrogen cycle is the dense storage of hydrogen. According to today's knowledge the maximum energy density attainable in a hydrogen storage material corresponds to

\footnotetext{
${ }^{\star}$ Correspondence: Dr. E. Callini

Tel.: +41216958212

E-mail: elsa.callini@epfl.ch,

aLaboratory of Materials for Renewable Energy (LMER)

Institute of Chemical Sciences and Engineering (ISIC)

Basic Science Faculty (SB)

École polytechnique fédérale de Lausanne (EPFL) Valais/Wallis

Energypolis, Rue de l'Industrie 17, CH-1950 Sion

'EMPA Materials Science \& Technology

Dübendorf
}

approximately $50 \%$ of the energy density of hydrocarbons. The addition of $\mathrm{CO}_{2}$ to the hydrogen cycle opens the possibility to reduce $\mathrm{CO}_{2}$ with hydrogen to hydrocarbons and therefore, store renewable energy in the form of hydrocarbons. The challenges are to extract $\mathrm{CO}_{2}$ from the atmosphere and to control the $\mathrm{CO}_{2}$ reduction reaction to a specific hydrocarbon product.

Hydrogen is the most abundant element in the Universe. Hydrogen can be produced in large quantities from water on demand, the solution to the fluctuation of energy fluxes, as a result of production of energy from renewable sources. Finding a material that allows hydrogen to be stored with a high hydrogen density and fast hydrogen sorption kinetics ${ }^{[1]}$ is required by most applications and, therefore, several options are under consideration. Liquefied hydrogen, pressurised tanks, metal hydrides or complex hydrides have been intensively investigated. However, the interactions of the hydrogen molecules or atoms with solid materials or surfaces are not known on an atomic level in complex hydrides. The identification of the decomposition reaction pathways of several complex hydrides, the determination of intermediate species in dehydrogenation reactions, the emission of side products, the role of catalysts are challenges ${ }^{[2]}$ that require the most advanced characterisation instrumentation and a profound knowledge of the chemical physics of the gas-solid interactions.

To close the hydrocarbon cycle by technical means, $\mathrm{CO}_{2}$ has to be captured from the atmosphere, i.e. separation of $\mathrm{CO}_{2}$ from $\mathrm{N}_{2}, \mathrm{O}_{2}$ and $\mathrm{H}_{2} \mathrm{O}$. The different properties, e.g. molecular size, molecular mass, interaction energy between the molecules and the surface, chemical reactivity and solubility of the molecules, allow the different molecules to be separated from each other. The selectivity, the kinetics and the energy requirement are the crucial parameters for the feasibility of a process. The gas molecules undergo chemical reaction when the orbitals of the surface of the solid, e.g. adsorbent or catalyst, start to overlap with the molecular orbitals of the gas molecules and can lead to the dissociation of the gas molecules and the binding of the fragment to the surface. Therefore, control of the surface structure, elemental composition and consequently electronic states determines the reactivity and the reaction pathway. The challenge of $\mathrm{CO}_{2}$ reduction to a 
longer chain hydrocarbon is in the reduction of oxygen and partially carbon with hydrogen and the simultaneous linking of the carbon atoms. In situ spectroscopic methods e.g. infrared, Raman, and X-ray photoelectron spectroscopy are essential for the analysis of the surface processes especially in combination with the investigation of the product gases by means of mass spectroscopy and gas chromatography. The experimental investigations are complemented by theoretical methods based on density functional and transition state theory. The understanding of the reaction mechanism will allow the development of new catalysts and to achieve full control of the $\mathrm{CO}_{2}$ reduction reaction to a specific hydrocarbon.

In this paper, we review some important achievements of our research on energy storage materials. The focus is on the importance of surface reactions to elucidate the addressed challenges and solutions we are providing to make a step forward to the closed energy material cycle for a sustainable future energy economy based on renewable sources.

\section{Hydrogen Storage in Complex Hydrides}

The storage of hydrogen requires materials that allow a high gravimetric and volumetric hydrogen density. The highest volumetric hydrogen density is found in metal hydrides. Complex hydrides exhibit a similar volumetric hydrogen density but with a gravimetric hydrogen density up to an order of magnitude higher than metal hydrides. The work of Bogdanovic, when he discovered that the addition of $\mathrm{TiCl}_{3}$ rendered the hydrogen sorption reactions in $\mathrm{NaAlH}_{4}$ reversible ${ }^{[3]}$ had a great impact on the research on hydrogen storage material. Ti catalyses the hydrogen sorption reaction in alanates and allows the measurement of pressure composition isotherms, i.e. the reaction equilibrates at each point of the isotherm. Some effects of Ti compound of the addition to borohydrides ${ }^{[4]}$ have been shown. ${ }^{[5]}$ However, the hydrogen desorption reaction from borohydrides is not catalysed by $\mathrm{Ti}$, when the system is exposed to a gas flow, ${ }^{[6]}$ as presented in Fig. 1. The reabsorption of hydrogen by the products of the desorption reaction requires high temperatures and high pressures. Furthermore, the reaction pathway for the hydrogen desorption is different from the absorption pathway and as a consequence the borohydrides do not equilibrate with the gas phase during the hydrogen sorption reactions. Ti in borohydrides leads to the formation of stable and volatile Ti-containing species, for example, $\left(\mathrm{Ti}\left(\mathrm{BH}_{4}\right)_{3}\right)$. This is a metathesis

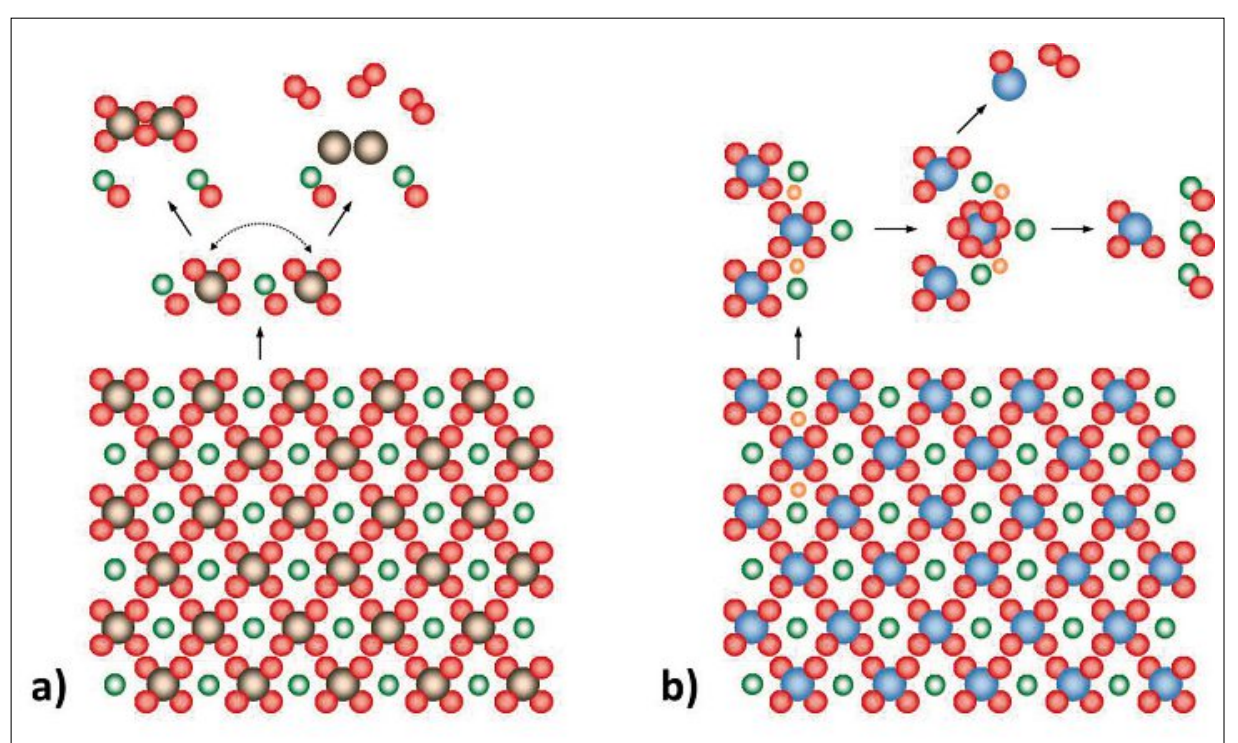

Fig. 1. Schematic representation of the hydrogen desorption from complex hydrides. a) Hydrogen desorption from a borohydride e.g. $\mathrm{LiBH}_{4}$. In the first step the alkali hydride $(\mathrm{LiH})$ is formed leaving two $\mathrm{BH}_{3}$ units behind. $\mathrm{BH}_{3}$ either decomposes and releases hydrogen or it combines with another $\mathrm{BH}_{3}$ to form a volatile $\mathrm{B}_{2} \mathrm{H}_{6}$. b) Hydrogen desorption from an alanate, e.g. $\mathrm{NaAlH}_{4}$. In the first step $2 \mathrm{NaH}$ from two neighbouring alanates are transferred to the central alanate to form the hexahydride $\mathrm{Na}_{3} \mathrm{AlH}_{6}$ leaving $2 \mathrm{AlH}_{3}$ behind which spontaneously decompose and release hydrogen. The hexahydride then forms $3 \mathrm{NaH}$ and $\mathrm{AlH}_{3}$ (

reaction, that is, a bimolecular process involving the exchange of bonds between the two reacting chemical species. Therefore, while for alanates the addition of $\mathrm{TiCl}_{3}$ has a catalytic effect, for borohydrides it leads to a metathesis reaction.

\section{Hydrogen Physisorption and Chemisorption}

The physisorption of hydrogen molecules at the material surface has been intensively investigated. ${ }^{[7]}$ Porous materials have a high specific surface area, where hydrogen molecules are adsorbed. [8] Palladium nanoparticles are able to split the dihydrogen bond and produce atomic hydrogen. When the metal nanoparticles are in close contact with a $\mathrm{H}$-atom host, chemisorption of $\mathrm{H}$-atoms by the host has been suggested to occur via the hydrogen spillover mechanism. ${ }^{[9]}$ Metal-organic frameworks were predicted to be able to act as effective chemisorption sites, and at ambient temperature increased hydrogen adsorption was reported on several occasions. ${ }^{[10]}$ The intimate contact was supposedly ensured by means of a carbon bridge. Palladium particles as catalyst were introduced into the MOF's pores and simultaneously ensured good contact, making the employment of the carbon bridge redundant. ${ }^{[11]}$ The addition of Pd nanoparticles increased the ambient-temperature hydrogen uptake of the framework, but this was found to be solely due to palladium hydride formation (Fig. 2, left). Spectroscopic sur- face investigations resolved the issue and showed that the hydrogen atoms do not chemisorb on the host framework, which excludes the possibility of hydrogen spillover.

\section{Hydrogen Interaction with Fullerenes}

$\mathrm{C}_{60}$, theoretically, has the potential to be a carbonaceous hydrogen storage material. A typical stable molecule is $\mathrm{C}_{60} \mathrm{H}_{36}{ }^{[12]}$ which has a hydrogen storage capacity of 4.8 mass $\% \mathrm{H}_{2}$. In $\mathrm{C}_{60} \mathrm{H}_{60}$ a capacity of 7.7 mass $\% \mathrm{H}_{2}$ is reached at temperatures up to $600{ }^{\circ} \mathrm{C}$ and 130 bar[13] but it also has been observed that prolonged hydrogenation ( $\mathrm{T}=400{ }^{\circ} \mathrm{C}, \mathrm{p}=120$ bar, up to 3000 min.) can lead to unwanted fragmentation of $\mathrm{C}_{60}{ }^{\cdot}{ }^{[14,15]}$

Karpushenkava et al. ${ }^{[16]}$ determined the standard enthalpy and entropy for the hydrogenation of fullerenes $\left(\mathrm{C}_{60}(\mathrm{~s})+18 \mathrm{H}_{2}(\mathrm{~g})\right.$ $\left.\rightarrow \mathrm{C}_{60} \mathrm{H}_{36}(\mathrm{~s})\right)$ to $\Delta H^{0}=-74.1 \mathrm{~kJ} \mathrm{~mol}^{-1} \mathrm{H}_{2}$ and $\Delta S^{0}=-126.2 \mathrm{~J} \mathrm{~mol}^{-1} \mathrm{H}_{2} \mathrm{~K}^{-1}$ ) (isomer mixture) leading to a decomposition temperature of $314{ }^{\circ} \mathrm{C}$ at a pressure of $1 \mathrm{bar}$ hydrogen. This enthalpy is comparable to relatively stable hydrides such as $\mathrm{MgH}_{2}{ }^{[17]}$ and $\mathrm{LiBH}_{4} \cdot{ }^{[18]}$

Metal-intercalated fullerides represent a new class of compounds for reversible hydrogen storage. By intercalating alkali or alkali earth metals into fullerene, the socalled fullerides are formed, where charges from the metal atoms are transferred to the fullerene cages. 


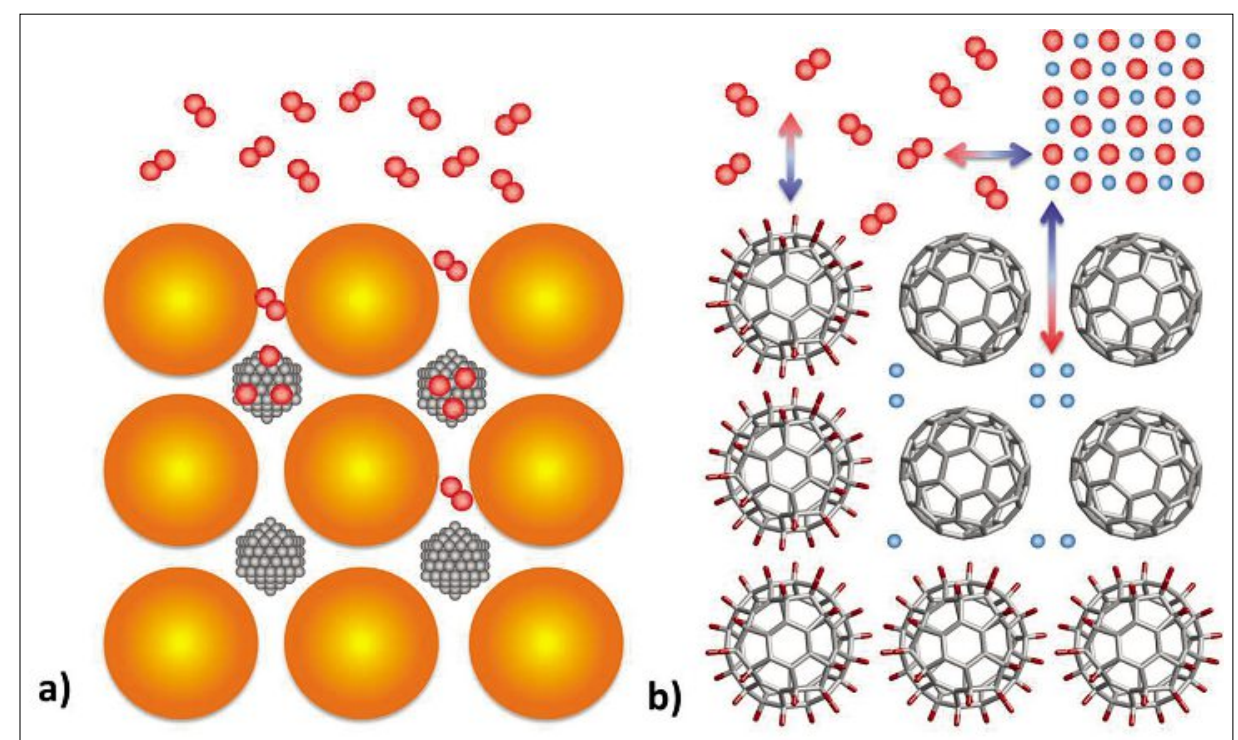

Fig. 2. Schematic illustration of the physisorption of hydrogen molecule on the surface of a Pddecorated MOF (left). Hydrogen molecules diffuse into the MOF and adsorb on the interior surface. Colour code: red is hydrogen, grey is Pd and yellow the MOF. Illustration for the mechanism of the reversible hydrogenation of $\mathrm{Li}_{12} \mathrm{C}_{60}$ (right). Deintercalation of $\mathrm{Li}$ out of the $\mathrm{Li}_{12} \mathrm{C}_{60}$ during hydrogen absorption (arrows: red to blue) leads to the formation of $\mathrm{LiH}$ and $\mathrm{Li}_{(12-x)} \mathrm{C}_{60} \mathrm{H}_{36+y^{*}}$. During hydrogen desorption (arrows: blue to red) of $\mathrm{Li}_{(12-x)} \mathrm{C}_{60} \mathrm{H}_{36+y}$ the $\mathrm{Li}$ from the decomposing $\mathrm{LiH}$ reintercalates into the $\mathrm{Li}_{(12-x)} \mathrm{C}_{60} \mathrm{H}_{36+y^{*}}$. Colours code: red is hydrogen, blue is Li, grey is $\mathrm{C}_{60}$ with and without hydrogen (spikes on $\mathrm{C}_{60}$ represent the attached hydrogen atoms).

Lithium/sodium fullerides can be synthesized by ball milling a stoichiometric mixture of pure $\mathrm{C}_{60}$ with the metal in an inert argon atmosphere for $15 \mathrm{~min}$ in a planetary ball mill and subsequent annealing at $270^{\circ} \mathrm{C}$. Alternatively sodium fulleride can be synthesized by mixing sodium azide $\left(\mathrm{NaN}_{3}\right)$ with $\mathrm{C}_{60}$ and annealing at $450{ }^{\circ} \mathrm{C}$.

The metal intercalation has two beneficial effects on the hydrogen sorption process. First, the heat of reaction can be lowered and as a second effect the kinetics of the sorption process is considerably increased.

In metal-intercalated fullerides up to $3.5^{[19]}\left(\mathrm{Na}_{10} \mathrm{C}_{60}-\mathrm{H}\right)$ and 5.1 mass\% $\mathrm{H}_{2}{ }^{[20]}$ $\left(\mathrm{Li}_{12} \mathrm{C}_{60}-\mathrm{H}\right)$ can be reversibly sorbed. Dehydrogenation enthalpies of 52 $\left(\mathrm{Na}_{10} \mathrm{C}_{60}-\mathrm{H}\right), 66\left(\mathrm{Li}_{12} \mathrm{C}_{60}-\mathrm{H}\right)$ and $69 \mathrm{~kJ} / \mathrm{mol}$ $\mathrm{H}_{2}\left(\mathrm{Li}_{28} \mathrm{C}_{60}-\mathrm{H}\right)$ were determined by DSC. These values are lower compared to the above-mentioned literature values. ${ }^{[16]}$ The onsets of hydrogen desorption are $185{ }^{\circ} \mathrm{C}$ $\left(\mathrm{Na}_{10} \mathrm{C}_{60}-\mathrm{H}\right), \quad 260{ }^{\circ} \mathrm{C} \quad\left(\mathrm{Li}_{12} \mathrm{C}_{60}-\mathrm{H}\right)$ and $250{ }^{\circ} \mathrm{C}\left(\mathrm{Li}_{28} \mathrm{C}_{60}-\mathrm{H}\right)$ compared to $>400^{\circ} \mathrm{C}$ for pure $\mathrm{C}_{60} \mathrm{H}_{36}{ }^{201]}$

During hydrogenation metal $(\mathrm{M})$ atoms deintercalate from the $\mathrm{M}_{2} \mathrm{C}_{60}$ phase and form $\mathrm{MH}$ in which hydrogen is ionically bound to $\mathrm{M}$ and at the same time in the remaining $\mathrm{M}$-depleted phase $\mathrm{M}_{\mathrm{z}-\mathrm{x}} \mathrm{C}_{60}$ hydrogen covalently binds to $\mathrm{C}_{60}$. During desorption, the reverse process takes place and $\mathrm{MH}$ reacts with the $\mathrm{M}_{\mathrm{z-x}} \mathrm{C}_{60} \mathrm{H}_{36+\mathrm{y}}$ phase by reintercalating $\mathrm{M}$ released from $\mathrm{MH}$ and forming $\mathrm{M}_{\mathrm{z}} \mathrm{C}_{60}$ again (see Fig. 2). The reversible hydrogen sorption can be described by the following reaction:

\section{Control of the Hydrogen Sorption Mechanisms}

At surfaces of hydrides, states of the surface control the hydrogen absorption and desorption kinetics. A metal surface is initially covered with surface oxide layers that hinder dissociation of hydrogen molecules. Hydrogen absorption by a host metal (into interstitial sites) is inhibited due to the difficulty in hydrogen dissociation and permeation in the surface oxide layers, depending on a rate-controlling step in the hydrogen absorption process (initial activation). [23]

Hydrogen desorption kinetics are controlled by formation of surface oxide layers which hinder recombination of hydrogen. The closed surface oxide layer on $\mathrm{AlH}_{3}$ prevents the thermodynamically unstable hydride from decomposing. [24]

At the surfaces of borohydrides, the surface oxidation of $\mathrm{LiBH}_{4}$ leads to segregation of $\mathrm{Li}$ oxide at the surface and to a disproportionated surface composition. The decomposition reaction of $\mathrm{LiBH}_{4}$ is accompanied by formation of gaseous products such as hydrogen as a main product and diborane as a by-product. The formation of a surface oxide layer such as $\mathrm{Li}_{2} \mathrm{O}$ has an impact on the diborane and the related hydrogen desorption. The diborane desorption is markedly suppressed by presence of the surface oxide layer, which retards formation of borane molecules due to the lowered mobility. Thus, desorption of hydrogen molecules is enhanced at the modified surface on the complex hydride. ${ }^{[25]}$

\section{$\mathrm{CO}_{2}$ Reduction on Metal Hydrides}

To store renewable energy in synthetic hydrocarbons, two major challenges have to be overcome: i) extraction of $\mathrm{CO}_{2}$ from the atmosphere close to the thermodynamic limit of energy need; ii) reduction of $\mathrm{CO}_{2}$ with hydrogen to specific hydrocarbons in a controlled end energy efficient reaction. ${ }^{[26]}$ Both challenges are directly related to interaction of $\mathrm{CO}_{2}$ with surfaces.

The catalytic reduction of $\mathrm{CO}_{2}$ is determined by the local availability of hydrogen atoms and the orientation of $\mathrm{CO}_{2}$ molecules. To control formation of $\mathrm{C}-\mathrm{C}$ bonds and reaction paths to synthesize specific energy-dense hydrocarbons from $\mathrm{CO}_{2}$, a new approach is $\mathrm{CO}_{2}$ reduction on a modified substrate based on metal-hydrogen systems (including metal clusters and nanoparticle compounds). In view of termination parameters for the chain growth in hydrocarbons, the thermodynamic potential of the intermediates is tailored by the binding energy of the carbon atom to the modified hydride substrate. 


\section{New Spectroscopic Approaches}

New tools have been developed for surface spectroscopy that allow on one side the local analysis of single molecules and on the other side the characterization of the surface state under real conditions i.e. while the surface is interacting with the gas molecules (Fig. 3).

Tip-enhanced Raman spectroscopy (TERS) is the combination of Ramanenhanced signals and scanning probe microscopies.[27] The advantage of such a system is the combination of topographic, morphological and chemical information of the surface. ${ }^{[28]}$ The Raman signal is enhanced by the tip of the microscope gaining intensity and making analysis possible on organic and low concentrated samples. The spatial resolution goes beyond the optical limit and therefore it allows the detection of changes on the surface on the nanometre scale. The collection of real time evolution signals allows fast evolving species to be monitored and the possibility of heating and cooling stages allows chemical and physical reactions to be following in real time.

Our instrument contributes to the creation of a spectroscopy facility, where scientists can perform Raman, atomic force microscopy, co-localized measurement, surface-enhanced Raman spectroscopy and TERS. The instrument is in a custom modified environment that allows full control of the temperature, partial pressure and atmosphere composition. Near ambient pressure X-ray photoelectron spectroscopy (NAP-XPS) is a powerful tool to analyse the electronic and chemical state of a surface as well as adsorbates under reaction conditions. NAP-XPS bridges a pressure gap between an ultra-high vacuum-based surface science experiment and an experiment simulating realistic conditions at mbar pressure, thus providing valuable information about interfacial reactions, gas-solid, gas-liquid, and liquid-solid reactions. [29]

For example, in heterogeneous catalysis, restructuring of a surface during reactions and the dependence of surface properties on pressure can be analysed in situ with respect to elemental composition, oxidation state, and chemical specificity of surfaces and adsorbates on the molecular scale at pressures of mbar or even higher. A correlation between surface chemistry and surface properties is determined by in situ surface analysis. The laboratory-based near ambient pressure XPS, combined with a versatile multi-technique UHV platform, allows immediate investigations and the sample environment can be perfectly controlled, i.e. no transport, no exposure to air and local synthesis of samples becomes possible.

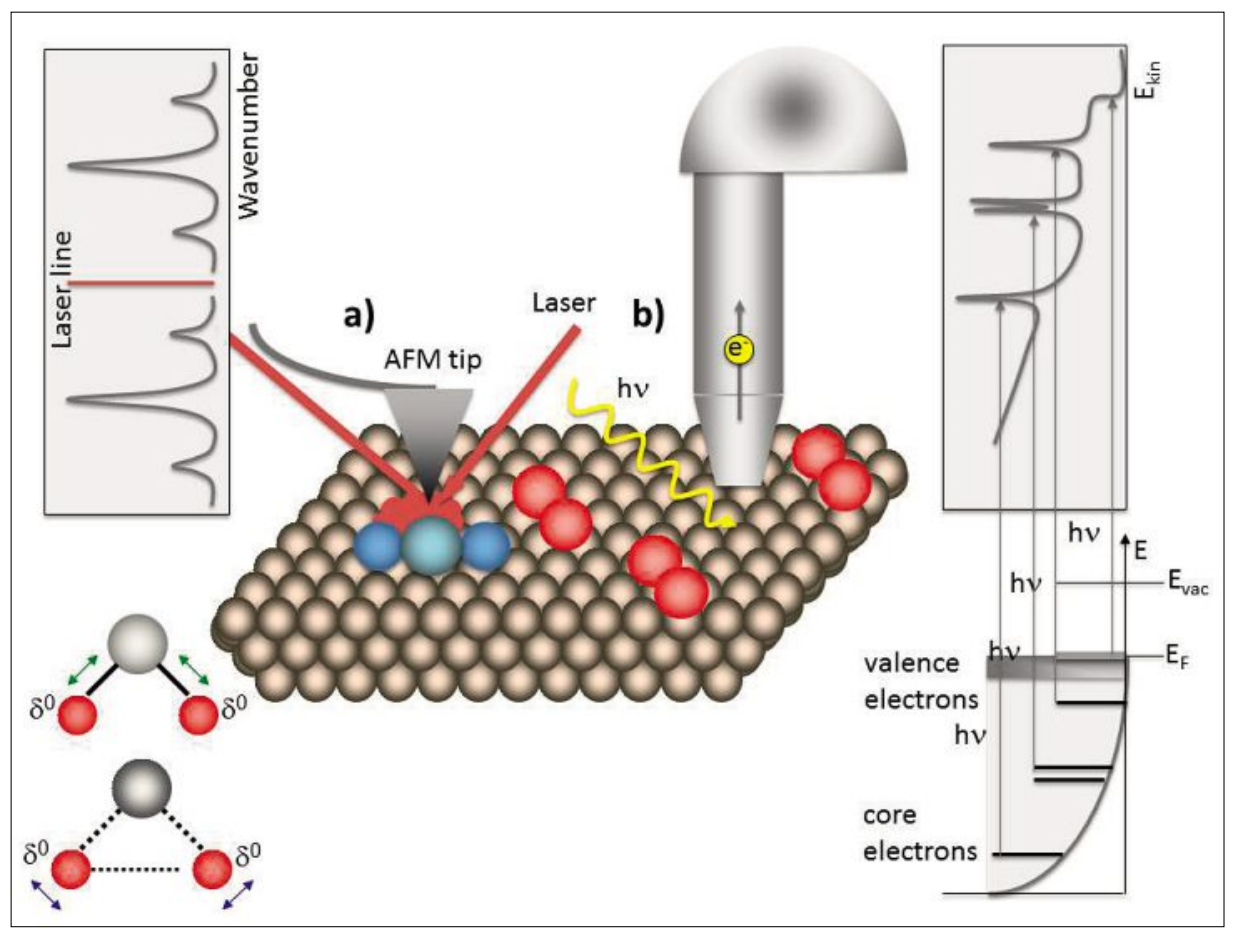

Fig. 3. Tip-enhanced Raman spectroscopy (TERS, left) and near ambient pressure X-ray photoelectron spectroscopy (NAP-XPS, right) on a surface exposed to gas molecules. TERS allows localising the probing region to a single molecule and amplifying the signal by several orders of magnitude. NAP-XPS allows probing photoelectrons on the sample surface exposed to up to mbar gas pressure.

\section{Conclusions}

The presented results demonstrate how the science of surfaces and surface reactions are crucial to understand the chemistry and physics behind the energy storage materials. The mechanism of the catalyst in the hydrogen sorption reaction of complex hydrides was successfully described and the special role of Ti in alanates, borohydrides and the $\mathrm{Ti}\left(\mathrm{BH}_{4}\right)_{3}$ was explained. The hydrogen spillover process on catalytic centres in nanoporous materials as well as the hydrogen intercallation in alkali metal decorated fullerenes was analysed and described in detail. Finally, the reaction pathway in the hydrogen desorption from borohydrides was successfully modified by the partial oxidation of the surface and, therefore, the creation of local diffusion barriers. $\mathrm{CO}_{2}$ reduction was investigated on the surface of a metal hydride, where a high concentration of atomic hydrogen is present. The new expansion of spectroscopic tools TERS and NAP-XPS is the basis for the detailed investigation of the $\mathrm{CO}_{2}$ reduction process.

Received: April 21, 2015

[1] Y. Nakamori, K. Miwa, A. Ninomiya, H. Li, N. Ohba, S. Towata, A. Züttel, S. Orimo, Phys. Rev. B 2006, 74, 045126; A. Züttel, A. Borgschulte, L. Schlapbach, 'Hydrogen as a Future Energy Carrier', Wiley-VCH, 2008.

[2] A. Borgschulte, A. Züttel, P. Hug, G. Barkhordarian, N. Eigen, M. Dornheim, R.
Bormann, A. J. Ramirez-Cuesta, Phys. Chem. Chem. Phys. 2008, 10, 4045; T. Frankcombe, Chem. Rev. 2012, 112, 2164; A. Borgschulte, E. Callini, B. Probst, A. Jain, S. Kato, O. Friedrichs, A. Remhof, M. Bielmann, A. Ramirez-Cuesta, A. Züttel, J. Phys. Chem. C 2011, 115, 17220.

[3] B. Bogdanovic, M. Schwickardi, J. Alloys Compd. 1997, 253, 1 .

[4] A. Züttel, P. Wenger, S. Rensch, P. Sudan, P. Mauron, C. Emmenegger, J. Power Sources 2003, 5194, 1 .

[5] M. Au, A. Jurgensen, K. Zeigler, J. Phys. Chem. B 2006, 110, 26482; T. Sun, H. Wang, Q. Zhang, D. Sun, X. Yao, M. Zhu, J. Mater. Chem. 2011, 21, 9179; O. Kircher, M. Fichtner, J. Alloys Compd. 2005, 404, 339; Q. Shi, X. Yu, R. Feidenhans'1, T.Vegge, J. Phys. Chem. C 2008, 112, 18244; G. Sandrock, K. Gross, G. Thomas, J. Alloys Comp. 2002, 339, 299.

[6] E. Callini, A. Borgschulte, C. L. Hugelshofer, A. J. Ramirez-Cuesta, J. Phys. Chem. C 2014, $118,77$.

[7] A. Züttel, P. Sudan, P. Mauron, T. Kiyobayashi, C. Emmenegger, L. Schlapbach, Int. J. Hydrogen Energy 2002, 27, 203.

[8] J. Sculley, D. Yuan, H.-C. Zhou, Energy Environ. Sci. 2011, 4, 2721; L. J. Murray, M. Dinca, J. R. Long, Chem. Soc. Rev. 2009, 38, 1294; D. Zhao, D. Yuan, H. C. Zhou, Energy Environ. Sci. 2008, 1, 222; M. P. Suh, H. J. Park, T. K. Prasad, D.-W. Lim, Chem. Rev. 2012, 112, 782; A. Züttel, Mater. Today 2003, 6, 24; J. L. Rowsell, O. M. Yaghi, J. Am. Chem. Soc. 2006, 128, 1304.

[9] Y. Li, R. T. Yang, J. Am. Chem. Soc. 2006, 128, 8136.

[10] Y. Li, R. T. Yang, AIChE J. 2008, 54, 269.

[11] P. A. Szilágyi, E. Callini, A. Anastasopol, C. Kwakernaak, S. Sachdeva, R. van de Krol, H. Geerlings, A. Borgschulte, A. Züttel, B. Dam, PhysChemChemPhys 2014, 16, 5803.

[12] R. E. Haufler, J. Conceicao, L. P. F. Chibante, Y. Chai, N. E. Byrne, S. Flanagan, M. M. Haley, 
S. C. O’Brien, C. Pan, Z. Xiao, W. E. Billups, M. A. Ciufolini, R. H. Hauge, J. L. Margrave, L. J. Wilson, R. F. Curl, R. E. Smalley, J. Phys. Chem. 1990, 94, 8634

[13] D. V. Schur, S. Y. Zaginaichenko, A. F. Savenko, V. A. Bogolepov, N. S. Anikina, A. D. Zolotarenko, Z. A. Matysina, T. N. Veziroglu, N. E. Skryabina, Int. J. Hydrogen Energy 2011, 36,1143 .

[14] A. V. Talyzin, Y. O. Tsybin, T. M. Schaub, P. Mauron, Y. M. Shulga, A. Züttel, B. Sundqvist, A. G. Marshall, J. Phys. Chem. B 2005, 109, 12742.

[15] A. V. Talyzin, Y. O. Tsybin, A. A. Peera, T M. Schaub, A. G. Marshall, B. Sundqvist, P. Mauron, A. Züttel, W. E. Billups, J. Phys. Chem. B 2005, 109, 5403.

[16] L. S. Karpushenkava, G. J. Kabo, V. V. Diky, Fuller. Nanotub. Car. N 2007, 15, 227.
[17] J. F. Stampfer, C. E. Holley, J. F. Suttle, J. Am. Chem. Soc. 1960, 82, 3504.

[18] P. Mauron, F. Buchter, O. Friedrichs, A. Remhof, M. Bielmann, C. N. Zwicky, A. Züttel, Phys. Chem. B 2008, 112, 906.

[19] P. Mauron, A. Remhof, A. Bliersbach, A. Borgschulte, A. Züttel, D. Sheptyakov, M Gaboardi, M. Choucair, D. Pontiroli, M. Aramini, A. Goerreri, M. Riccò, Int. J. Hydrogen Energy 2012, 37, 14307.

[20] P. Mauron, M. Gaboardi, A. Remhof, A. Bliersbach, D. Sheptyakov, M. Aramini, G. Vlahopoulou, F. Giglio, D. Pontiroli, M. Riccò, A. Züttel, Phys Chem C 2013, 117, 22598.

[21] A. A. Peera, L. B. Alemany, W. E. Billups, Appl. Phys. A 2004, 78, 995.

[22] P. Mauron, M. Gaboardi, D. Pontiroli, A. Remhof, M. Riccò, A. Züttel, Phys Chem C 2015, 119, 1714 .
[23] E. Fromm, H. Uchida, B. Chelluri, Ber. Bunsen. Phys. Chem. 1983, 87, 410 .

[24] S. Kato, M. Bielmann, K. Ikeda, S. Orimo, A. Borgschulte, A. Züttel, Appl. Phys. Lett. 2010 , 96, 051912.

[25] S. Kato, M. Bielmann, A. Borgschulte, V. Zakaznova-Herzog, A. Remhof, S. Orimo, A Züttel, PhysChemChemPhys 2010, 12, 10950.

[26] A. Züttel, P. Mauron, S. Kato, E. Callini, M. Holzer, J. Huang, Chimia 2015, 69, 264

[27] M. Osawa, T. Hasegawa, Anal. Bioanal. Chem. 2007, 388, 5; T. Pettinger, P. Schambach, C. J. Villagómez, N. Scott, Annu. Rev. Phys. Chem. 2012, 63, 379; C. Blum, T. Schmid, L. Opilik, S. Weidmann, S. Fagerer, R. Zenobi, J. Raman Spectrosc. 2012, 42, 1895.

[28] T. Schmid, L. Opilik, C. Blum, R. Zenobi, Angew. Chem. Int. Ed. 2013, 52, 5940.

[29] D. E. Starr, Z. Liu, M. Hävecker, A. KnopGerickec, H. Bluhm, Chem. Soc. Rev. 2013, 42, 5833. 